\title{
Comparison of Efficacy of Telephysiotherapy with Supervised Exercise Programme in Management of Patients Suffering with Grade I and II Osteoarthritis
}

\author{
Pratiksha Dighe and Twinkle Dabholkar
}

\begin{abstract}
Aim: The aim of this study was to investigate the effect of a 4-week Telephysiotherapy programme on quality of life of patients with osteoarthritis of the knee using smart phone application medium which is widely available, affordable and relevant telecommunication in India. Method: Patients meeting the inclusion criteria were recruited to the study by convenient sampling method and then alternately assigned to the two groups: Group A (Telephysiotherapy) and Group B (Supervised exercise programme). For the first 2 weeks, patients in both groups received conventional physiotherapy treatment 3 sessions/week. After the second week, Group A received standardized exercise programme through mobile application and was notified 3 times a week for additional 4 weeks. Group B received supervised exercise programme 3 times a week at clinical setting (OPD) for additional 4 weeks. No telephonic coaching or monitoring was done for this group. Patients were assessed pre-post intervention for pain (on NPRS), knee range of motion, knee muscle strength and flexibility, balance and proprioception, and physical function (on WOMAC). Standardized exercise programme was planned and delivered to the patients. Results: All outcome measures showed significant improvement in both groups $(\mathrm{p}<005)$. On between group comparisons, there was no significant difference on all outcome measures except balance. On comparing cost effectiveness within group cost expenditure for treatment was lower in Telephysiotherapy group. Conclusion: This indicates that the Telephysiotherapy showed comparable improvements on impairments and functional outcome measure (WOMAC), when compared to supervised therapy group in the management of patients with osteoarthritis of the knee. Also, it had an additional benefit on balance scores and was more cost effective than supervised therapy group. Hence, it can be considered as a feasible mode of treatment.
\end{abstract}

\section{Pratiksha Dighe}

MPT in Musculoskeletal conditions

D.Y. Patil School of Physiotherapy

D.Y. Patil University

Nerul, Navi Mumbai,India

E-mail: pratikshadighe95@gmail.com

Twinkle Dabholkar

Professor and Head

Department of Musculoskeletal Physiotherapy

D.Y. Patil School of Physiotherapy

D.Y. Patil University

Nerul, Navi Mumbai,India

E-mail: twinkledabholkar@rediffmail.com
Key Words: Telephysiotherapy,

Knee osteoarthritis, Mobile application, Cost effectiveness, WOMAC

DOI: $10.18376 / j e s p / 2020 / v 16 / 11 / 154131$ 


\section{Journal of Exercise Science \& Physiotherapy Vol. 16 No. 1 (January to June) 2020 \\ ISSN: 0973-2020 (Print) I I OR Impact Factor $=6.850 \quad$ ISSN: 2454-6089 (Online)}

\section{Introduction}

Knee Osteoarthritis (OA) is prevalent musculoskeletal condition affecting elderly causing pain, physical disability and reduction in quality of life. Hip and knee osteoarthritis is ranked as the $11^{\text {th }}$ highest contributor to global disability and $38^{\text {th }}$ highest in disability adjusted years. From 1990 to 2010 the global age standardised prevalence of knee osteoarthritis was 3.8\% with no discernible change (Cross et al., 2014). Knee osteoarthritis prevalence in India was reported by Chandra Prakash Pal et al to be $28.7 \%$ with associatedfactors being female gender, obesity, age and sedentary work (Pal et al., 2016). There is an increase in the years lost due to disability (YLDs) for hip and knee OA, from 10.5 million in 1990 (0.42\% of total DALYs) to 17.1 million in 2010 ( $0.69 \%$ of total DALYs) as reported in estimates from global burden of disease 2010 study. Due to aging and increasing obesity of world's population, health professions need to prepare for a large increase in demand for health services to treat knee and hip osteoarthritis (Cross et al., 2014). Physiotherapy treatment for Knee OA involves therapeutic exercises which are desirable and supported by high quality evidence (Jamtvedt et al.,2008).Telephysiotherapy provides physiotherapists a new and innovative way to deliver treatment known effectiveness using modern technology. Enhanced digital connectivity has greatly improved the scope and acceptance of telephysiotherapy for patient care. It provides access to effectivehealth care, opportunity to reduce disability and enhance wellness. According to American Telemedicine Association, telemedicine is defined as the remote delivery of healthcare services and clinical information using telecommunications technology such as internet, wireless, satellite, and telephone media (American Telemedicine Association about Telemedicine website, 2018). It is documented that the dimension of distance in Telemedicine could be bridged with the help of communication technologies ranging from simple old telephone system to ICT and networking technologies, such as Internet, Global System for Mobile Communications (GSM), computer networks, etc. (Sood et al., 2007). The term "mHealth" is a subcategory of "e Health" (electronic health) refers to the concept of using mobile devices such as mobile phones, tablets, and smartphones, in medicine and public health (Dicianno et al., 2015). mHealth is seen as an enabler of change worldwide because of its high reach and low-cost solutions(Dicianno et al., 2015). Smartphone applications part of telemedicine have been used for effective treatment of musculoskeletal disorders like OA knee (Odole and Ojo 2014; Azma et al., 2018; Rao et al., 2012; Odole and Ojo 2013), Low back pain (Multani et al., 2006 ; Truter 2013), post Total Knee Replacement (Russell 2011). Odole and Ojo (2014) documented that the telephone-based physiotherapy intervention is effective in management of patients with knee osteoarthritis. Tousignant et al, (2015) stated that the cost for a single session of in home telerehabilitation compared to conventional home visit rehabilitation was lower or about the same, depending on the distance between the patient's home and health care centre. Jack et al., (2013) and Jamtvedt et al., (2008) have suggested that the impact on a physical, social, and psychological status should be evaluated for any new therapeutic interventions in patients suffering from knee OA. Although patients are digitally well connected the acceptance and usability of telemedicine in a culturally varied background in our country, needs to be determined. With respect to exercise management of OA, it was recommended that future studies must identify cost-effective exercise modes, strategies to maximize exercise compliance and optimal treatment combinations.(Bennell and Hinman 2005). Hence, the primary objective of our study was to investigate the effect of a 4-week Telephysiotherapy programme on impairments and quality of life of patients with osteoarthritis of the knee using Smartphone application that is widely available, affordable and relevant telecommunication in India. The secondary objective of our study is to assess and compare cost effectiveness of an internet based telerehabilitation programme compared with supervised therapy group. 


\section{Journal of Exercise Science \& Physiotherapy Vol. 16 No. 1 (January to June) 2020 ISSN: 0973-2020 (Print) $\quad$ I $_{2}$ OR Impact Factor $=6.850 \quad$ ISSN: 2454-6089 (Online)}

\section{Materials and Method}

This study was conducted in D. Y. Patil Hospital and Research Centre, Nerul, Navi Mumbai. Seventy six patients, both male and female, suffering from grade I and II osteoarthritis of knee joint (Kellgren and Lawrence classification), were included in the study. Other inclusion criteria was literate patients having access to smartphone with internet connectivity. Patients were excluded from our study if they were suffering from other type of arthritis, severe osteoarthritis (grade III and IV), currently receiving regular physiotherapy or other non-drug management, knee surgery and history of intra-articular corticosteroid injection within past six months. Institutional Ethical Committee approval was obtained prior to conducting the study. A written informed consent was obtained from the patients prior to recruitment, after explaining the study procedure, benefits and risk.

\section{Intervention}

After recruiting the patients by convenient sampling method, alternate allocation of eligible patients was done to one of the 2 groups i.e. Group A (Telephysiotherapy group) and Group B (Supervised Physiotherapy Group). Both the group received supervised outpatient treatment for 3 times a week up to 2 weeks (6 sessions), since initial pain levels were moderate. In initial 2 weeks hot fomentation and Mulligan mobilizations were given for the reduction of pain. The treatment session lasted for 20-25 minutes for both the groups. Standardized exercise programme was planned and delivered to the patients. Minor differences were made in some exercises according to the baseline assessment of the patient. Patients in both the groups carried out some common exercises like were static quadriceps, static hamstring, hip and knee strengthening, dynamic quadriceps, and those targeting balance and proprioception. After second week patients in Telephysiotherapy group(Group A) received standardized exercise programme through mobile application and was notified 3 times a week for 4 week. Telephonic monitoring was done using uniform statements and coaching was done during 2 week follow-up session. Patient's documentation was done through application. Patients in Supervised Physiotherapy Group (Group B), received supervised exercise programme 3 times a week at outpatient department for 4 weeks. No telephonic coaching or monitoring was done for this group. Both the group were assessed for the below mentioned outcome measures pre-treatment, $2^{\text {nd }}$ week and $6^{\text {th }}$ week post treatment. Since the treatment for both groups was common for the first 2 weeks, for statistical analysis the $2^{\text {nd }}$ week reading was taken as baseline and $6^{\text {th }}$ week was taken as post-treatment. The outcome measures were as follows:

1. Knee pain at rest and activity was measured on Numeric Pain Rating Scale (NPRS)

2. Knee range of motion was assessed using Universal goniometer

3. Muscle strength of the Quadriceps and Hamstring measured on 0-5 grading

4. Muscle flexibility: Flexibility of quadriceps was measured with by recording the knee flexion range achieved in prone, hamstring by knee extension range at the 90-90 test and tendoachilles by dorsiflexion range with the knee extended.

5. Balance \& Proprioception: Single leg stance test was performed with eyes open and arms by the side of body. The patient must stand unassisted on one leg and is timed in seconds from the time one foot is flexed off the floor to the time when it touches the ground or the standing leg. Participants unable to perform the one leg stand for at least 5 seconds are at increased risk for injurious fall (Bennell 2005). Single leg stance or unipedal stance test was used in our study to evaluate balance and proprioception. This test is often used to assess static postural and balance control. As $40 \%$ of human gait movement occurs on one leg stance, it is important to include this standardized test in every patient assessment regardless of age.

6. Physical function and disability: Pain, stiffness and disability was assessed using the Western Ontario and McMaster Universities Osteoarthritis Index (WOMAC) which is a questionnaire that evaluates the condition of patients with OA knee using 24 parameters which is divided into three 
subscales. The pain, stiffness and physical function subscales fulfil conventional criteria for face, content and construct validity, reliability, responsiveness and relative efficiency. Hence WOMAC it is recommended use as a disease-specific evaluative research in osteoarthritis clinical trials (Bellamy et al., 1988).

7. To calculate the cost expenditure for treatment the cost effectiveness analysis included the cost of transportation, OPD charges and internet usage cost in this study.

The statistical analysis of the data was done using the "SPSS 23 " software and $95 \%$ confidence level was used so that level of significance was set at $p=0.05$, two-tailed. Since the treatment for both groups was common for the first 2 weeks, for statistical analysis the $2^{\text {nd }}$ week reading was taken as baseline and $6^{\text {th }}$ week was taken as post-treatment. For within group comparison of outcome measures of pain, knee strength, balance and proprioception, and physical function (WOMAC), analysis was done by using Wilcoxon signed ranked test. Paired t-test was used for within group comparison of knee ROM, Flexibility of Quadriceps, Hamstrings, Tendoachilles. For between group comparison of demographic data, cost effectiveness, knee range, muscle flexibility, independent sample t-test was used. Whereas, between group comparison of pain, knee muscle strength, balance and proprioception, physical function (WOMAC), the analysis was done using Man Whitney U test.

Results

Table 1.The demographic data of the patients

\begin{tabular}{|c|c|c|c|}
\hline Demographic Data & $\begin{array}{c}\text { Group A } \\
\text { (Telephysiotherapy) }\end{array}$ & $\begin{array}{c}\text { Group B(Supervised } \\
\text { therapy) }\end{array}$ & $\begin{array}{c}\text { P - } \\
\text { value }\end{array}$ \\
\hline Age & $52.06 \pm 6.30$ & $54.87 \pm 8.69$ & 0.14 \\
\hline Gender (F:M) & $21: 12$ & $25: 6$ & 0.17 \\
\hline $\begin{array}{c}\text { Body Mass Index } \\
\text { (BMI) }\end{array}$ & $24.70 \pm 3.68$ & $26.00 \pm 3.06$ & 0.17 \\
\hline
\end{tabular}

Table 1 shows the statistical analysis of the demographic parameters revealed no difference between the groups.

Table 2. Results of within group (pre-intervention and post intervention) comparison of all outcome measures

\begin{tabular}{|c|c|c|c|}
\hline $\begin{array}{l}\text { Sr. } \\
\text { No }\end{array}$ & Outcome Variable & $\begin{array}{l}\text { Telephysiotherapy } \\
\text { Group (Mean } \pm \text { SD) }\end{array}$ & $\begin{array}{l}\text { Supervised Therapy } \\
\text { Group(Mean } \pm \text { SD) }\end{array}$ \\
\hline \multirow[t]{3}{*}{1} & $\begin{array}{l}\text { Activity Pain } \\
\text { Pretreatment (NPRS) }\end{array}$ & $4.22 \pm 1.64$ & $5.11 \pm 2.07$ \\
\hline & $\begin{array}{l}\text { Activity Pain post- } \\
\text { treatment }\end{array}$ & $0.66 \pm 0.82$ & $0.86 \pm 0.93$ \\
\hline & $\mathrm{P}$ value & $0.00 *$ & $0.00 *$ \\
\hline \multirow[t]{3}{*}{2} & $\begin{array}{l}\text { ROM knee flexion } \\
\text { Pretreatment }\end{array}$ & $117.17^{\circ} \pm 12.03$ & $117.78^{\circ} \pm 11.58$ \\
\hline & $\begin{array}{l}\text { ROM knee flexion } \\
\text { Post-treatment }\end{array}$ & $128.68^{\circ} \pm 7.14$ & $130.92^{\circ} \pm 7.24$ \\
\hline & $\mathrm{P}$ value & $0.00 *$ & $0.00 *$ \\
\hline
\end{tabular}


Journal of Exercise Science \& Physiotherapy Vol. 16 No. 1 (January to June) 2020 ISSN: 0973-2020 (Print) $\mathrm{I}_{2} \mathrm{OR}$ Impact Factor $=6.850 \quad$ ISSN: 2454-6089 (Online)

\begin{tabular}{|c|c|c|c|}
\hline 3 & $\begin{array}{l}\text { Strength knee flexor } \\
\text { pre treatment (MMT) }\end{array}$ & $3.56 \pm 0.50$ & $3.44 \pm 0.50$ \\
\hline & $\begin{array}{l}\text { Strength knee flexor } \\
\text { post-treatment }\end{array}$ & $4.27 \pm 0.45$ & $4.33 \pm 0.48$ \\
\hline & $\mathrm{P}$ value & $0.00 *$ & $0.00 *$ \\
\hline \multirow[t]{3}{*}{4} & $\begin{array}{l}\text { Strength knee } \\
\text { extensor } \\
\text { pretreatment (MMT) }\end{array}$ & $3.73 \pm 0.50$ & $3.53 \pm 0.51$ \\
\hline & $\begin{array}{l}\text { Strength knee extensor } \\
\text { post-treatment }\end{array}$ & $4.39 \pm 0.49$ & $4.44 \pm 0.50$ \\
\hline & $\mathrm{P}$ value & $0.00 *$ & $0.00 *$ \\
\hline \multirow[t]{3}{*}{5} & $\begin{array}{l}\text { Flexibility } \\
\text { Quadriceps } \\
\text { pretreatment }\end{array}$ & $117.56^{\circ} \pm 11.57$ & $117.78^{\circ} \pm 11.58$ \\
\hline & $\begin{array}{l}\text { Flexibility Quadriceps } \\
\text { Post-treatment }\end{array}$ & $128.68^{\circ} \pm 7.14$ & $130.92^{\circ} \pm 7.24$ \\
\hline & $\mathrm{P}$ value & $0.00 *$ & $0.00 *$ \\
\hline \multirow[t]{3}{*}{6} & $\begin{array}{l}\text { Flexibility } \\
\text { Hamstrings } \\
\text { pretreatment }\end{array}$ & $24.07^{\circ} \pm 11.57$ & $23.11^{\circ} \pm 16.17$ \\
\hline & $\begin{array}{l}\text { Flexibility Hams post- } \\
\text { treatment }\end{array}$ & $17.95^{\circ} \pm 7.14$ & $16.67^{\circ} \pm 12.94$ \\
\hline & $\mathrm{P}$ value & $0.00 *$ & $0.00 *$ \\
\hline \multirow[t]{3}{*}{7} & $\begin{array}{l}\text { Flexibility Tendo- } \\
\text { Achilles pretreatment }\end{array}$ & $16.56^{\circ} \pm 2.52$ & $15.39^{\circ} \pm 2.45$ \\
\hline & $\begin{array}{l}\text { Flexibility Tendo- } \\
\text { Achilles post }\end{array}$ & $19.76^{\circ} \pm 0.80$ & $19.61^{\circ} \pm 0.80$ \\
\hline & $\mathrm{P}$ value & $0.00 *$ & $0.00 *$ \\
\hline \multirow[t]{3}{*}{8} & $\begin{array}{l}\text { Balance on Single leg } \\
\text { stancepretreatment } \\
\text { (secs) }\end{array}$ & $17.39 \pm 4.23$ & $17.18 \pm 4.99$ \\
\hline & $\begin{array}{l}\text { Balance on single leg } \\
\text { stance post-treatment }\end{array}$ & $33.09 \pm 5.10$ & $29.67 \pm 5.92$ \\
\hline & $\mathrm{P}$ value & $0.001 *$ & $0.00 *$ \\
\hline \multirow[t]{3}{*}{9} & $\begin{array}{l}\text { WOMAC } \\
\text { pretreatment }\end{array}$ & $38.29 \pm 22.09$ & $40.22 \pm 20.08$ \\
\hline & $\begin{array}{l}\text { WOMAC post- } \\
\text { treatment }\end{array}$ & $10.68 \pm 8.36$ & $12.22 \pm 9.45$ \\
\hline & $\mathrm{P}$ value & $0.00 *$ & $0.00 *$ \\
\hline
\end{tabular}

Table 2 shows within group comparison of 4 weeks of treatment consisting of supervised exercise program or telephysiotherapy both led to reduce pain, improved range of motion, muscle flexibility and strength, balance and proprioception and physical function in both groups. 
Journal of Exercise Science \& Physiotherapy Vol. 16 No. 1 (January to June) 2020 ISSN: 0973-2020 (Print) I I OR Impact Factor $=6.850 \quad$ ISSN: 2454-6089 (Online)

Table 3. Results of between group (pre-intervention and post intervention) comparison of all outcome measures

\begin{tabular}{|c|c|c|c|c|}
\hline $\begin{array}{l}\text { Sr } \\
\text { No }\end{array}$ & Outcome Measure & $\begin{array}{l}\text { Telephysiotherapy } \\
\text { Group (Mean } \pm \text { SD) }\end{array}$ & $\begin{array}{l}\text { Supervised Therapy } \\
\text { Group(Mean } \pm \text { SD) }\end{array}$ & $\begin{array}{c}\text { Sig. } \\
(\mathrm{P}- \\
\text { value) }\end{array}$ \\
\hline \multirow[t]{2}{*}{1} & $\begin{array}{l}\text { Pain on Activity } \\
\text { Pre-treatment }\end{array}$ & $4.22 \pm 1.64$ & $5.11 \pm 2.07$ & 0.052 \\
\hline & $\begin{array}{l}\text { Pain on Activity post- } \\
\text { treatment }\end{array}$ & $0.66 \pm 0.82$ & $0.86 \pm 0.93$ & 0.32 \\
\hline \multirow[t]{2}{*}{2} & $\begin{array}{l}\text { ROM knee flexion } \\
\text { Pretreatment }\end{array}$ & $117.17^{\circ} \pm 12.03$ & $117.78^{\circ} \pm 11.58$ & 0.82 \\
\hline & $\begin{array}{l}\text { ROM knee flexion } \\
\text { Post-treatment }\end{array}$ & $128.68^{\circ} \pm 7.14$ & $130.92^{\circ} \pm 7.24$ & 0.17 \\
\hline \multirow[t]{2}{*}{3} & $\begin{array}{l}\text { Strength knee } \\
\text { flexor pre-treatment } \\
\text { (MMT) }\end{array}$ & $3.56 \pm 0.50$ & $3.44 \pm 0.50$ & 0.31 \\
\hline & $\begin{array}{l}\text { Strength knee flexor } \\
\text { post-treatment }\end{array}$ & $4.27 \pm 0.45$ & $4.33 \pm 0.48$ & 0.53 \\
\hline \multirow[t]{2}{*}{4} & $\begin{array}{l}\text { Strength knee } \\
\text { extensor pre- } \\
\text { treatment (MMT) }\end{array}$ & $3.73 \pm 0.50$ & $3.53 \pm 0.51$ & 0.08 \\
\hline & $\begin{array}{l}\text { Strength knee } \\
\text { extensor post- } \\
\text { treatment }\end{array}$ & $4.39 \pm 0.49$ & $4.44 \pm 0.50$ & 0.63 \\
\hline \multirow[t]{2}{*}{5} & $\begin{array}{l}\text { Flexibility } \\
\text { Quadriceps pre- } \\
\text { treatment }\end{array}$ & $117.56^{\circ} \pm 11.57$ & $117.78^{\circ} \pm 11.58$ & 0.94 \\
\hline & $\begin{array}{l}\text { Flexibility Quadriceps } \\
\text { Post-treatment }\end{array}$ & $128.68^{\circ} \pm 7.14$ & $130.92^{\circ} \pm 7.24$ & 0.18 \\
\hline \multirow[t]{2}{*}{6} & $\begin{array}{l}\text { Flexibility } \\
\text { Hamstrings pre- } \\
\text { treatment }\end{array}$ & $24.07^{\circ} \pm 11.57$ & $23.11^{\circ} \pm 16.17$ & 0.78 \\
\hline & $\begin{array}{l}\text { Flexibility Hams post- } \\
\text { treatment }\end{array}$ & $17.95^{\circ} \pm 7.14$ & $16.67^{\circ} \pm 12.94$ & 0.63 \\
\hline \multirow[t]{2}{*}{7} & $\begin{array}{l}\text { Flexibility Tendo- } \\
\text { Achilles pre- } \\
\text { treatment }\end{array}$ & $16.56^{\circ} \pm 2.52$ & $15.39^{\circ} \pm 2.45$ & 0.62 \\
\hline & $\begin{array}{l}\text { Flexibility Tendo- } \\
\text { Achilles post- } \\
\text { treatment }\end{array}$ & $19.76^{\circ} \pm 0.80$ & $19.61^{\circ} \pm 0.80$ & 0.43 \\
\hline \multirow[t]{2}{*}{8} & $\begin{array}{l}\text { Balance pre- } \\
\text { treatment (Single leg } \\
\text { stance) }\end{array}$ & 17.39 & 17.18 & 0.79 \\
\hline & $\begin{array}{l}\text { Balance post- } \\
\text { treatment }\end{array}$ & 33.09 & 29.67 & $0.00 *$ \\
\hline \multirow[t]{2}{*}{9} & $\begin{array}{l}\text { WOMAC pre- } \\
\text { treatment }\end{array}$ & $38.29 \pm 22.09$ & $40.22 \pm 20.08$ & 0.78 \\
\hline & $\begin{array}{l}\text { WOMAC post- } \\
\text { treatment }\end{array}$ & $10.68 \pm 8.36$ & $12.22 \pm 9.45$ & 0.49 \\
\hline
\end{tabular}




\section{Journal of Exercise Science \& Physiotherapy Vol. 16 No. 1 (January to June) 2020 \\ ISSN: 0973-2020 (Print) $\quad$ I $_{2}$ OR Impact Factor $=6.850 \quad$ ISSN: 2454-6089 (Online)}

Table 3 shows between group comparisons, there was no difference between the outcome measures indicating comparable improvement in both groups, except there was statistically significantly more improvement in balance and proprioception in the Telephysiotherapy group. Table 4. Statistical analysis of the between group comparison
of cost analysis post-intervention

\begin{tabular}{|l|c|c|c|}
\hline Group & N & $\begin{array}{c}\text { Total Cost } \\
(\text { Mean +/- SD })\end{array}$ & $\begin{array}{c}\text { Sig. } \\
(2 \text { tailed })\end{array}$ \\
\hline Supervised physiotherapy & 31 & $2541(1419)$ & \multirow{2}{*}{$0.00 *$} \\
\cline { 1 - 3 } Tele physiotherapy & 33 & $1367(812)$ & \\
\hline
\end{tabular}

*p value for Independent sample T- test

Table 4 shows a statistical comparison of total cost incurred in both groups showed that there was significantly low cost incurred in Telephysiotherapy group as compared to the Supervised Physiotherapy group $(\mathrm{p}<0.05)$.

\section{Discussion}

The aim of the present study was to compare the effect of the Telephysiotherapy with supervised exercise program on knee pain, range of motion, muscle strength and flexibility, balance and proprioception and physical function in patient suffering with grade I and II osteoarthritis after 4 weeks of intervention. The results of our study indicates that 4 weeks of treatment consisting of either supervised exercise program or Telephysiotherapy, delivered through mobile application, led to comparable improvement on all outcome measures, except balance which showed more improvement in Telephysiotherapy group as compare to supervised therapy group. Previous studies indicate beneficial effect of supervised Physiotherapy management (Abbott et al., 2013; Deyle et al., 2005; Ganjave and Twinkle 2017).Similar improvements were reported in the group undergoing Supervised PT in our study. Exercises were the mainstay of management in our treatment in both supervised physiotherapy and Telephysiotherapy group. It is postulated that treatments such as physical exercise, muscle strengthening, motor control, functional tasks training, and education strategies are able to activate relevant cortical areas for positive cortical reorganization and cause pain modulation at the central level. This aforementioned mechanism could be the reason for post treatment pain reduction with exercise training in both the groups (Gosling 2012). The mechanism for improvement in balance in patients in our study could be attributed to incorporation of strengthening exercises and balance exercises in weight bearing position which are supported by previous literature in knee OA patients (Ganjave and Twinkle 2017; Rogers et al., 2011; Silva et al., 2012; Diracoglu et al., 2005). Also, pain reduction could have been a reason for improvement in the balance as it can increase the standing tolerance time (Kim et al., 2016). Our study results showed significantly improved functional abilities on WOMAC in both groups on within group analysis, with no significant difference on between group comparison. It may be hypothesized that improvement in muscle strength, balance and exercise adherence could be the reason for reduced pain and disability and improvement in physical performance (Rogers et al., 2011; Ağlamış et al., 2009; Dinçer et al.,2006). In addition, the exercise program aimed to increase individuals' confidence in the use of their knee and overcome the fear of physical activity (Bhatt et al., 2015). The significant improvement on all outcome measures in the Telephysiotherapy group (Group A) could be attributed to the exercise management. Results of our study showed improvement in 


\section{Journal of Exercise Science \& Physiotherapy Vol. 16 No. 1 (January to June) 2020 ISSN: 0973-2020 (Print) $\quad \mathrm{I}_{2} \mathrm{OR}$ Impact Factor $=6.850 \quad$ ISSN: 2454-6089 (Online)}

muscle flexibility of Quadriceps, Hamstring, Tendo- achilles after exercises protocol which included, muscle stretching, ROM and strength training, delivered through mobile application for 4 weeks. Similar improvements in knee muscle strength, range of motion and functional capacity (Lequesne index) and pain reduction have been reported by Carvalho et al., (2010) but with manual guided home based exercise program in patients with knee osteoarthritis (Carvalho et al., 2010). Carvalho et al.,(2010) administered a home based exercise protocol that contained photographs and guidance, consisting of physical stretching and muscle strengthening exercises in patients with knee osteoarthritis, whereas we have used Telephysiotherapy as a remote mode of treatment delivery. Moreover, Telephysiotherapy provides the patient with a sense of personal autonomy and empowerment (Brennan et al., 2009). It engages the patients as more active partner rather than a passive participant in their care. Other advantage of Tele physiotherapyis that, it enables access to health care for individuals in remote areas or for those who have mobility issues associated with physical impairment, access to transport and socioeconomic factors. Additionally, it reduces the associated travel costs and time spent travelling for both the healthcare provider and the patient (Theodoros et al., 2008; Kairy et al., 2009).Important to note is that therapeutic non-compliance has been associated with excess urgent care visits, hospitalizations and higher treatment costs(Jin et al., 2008). Future research should be carried out by using Telephysiotherapy, as a mode of treatment for various heath related pathological conditions, carefully considering the risk and benefits of such a system. Our study design, which comprised of adequate time of training with the device, could be a desirable model that could be followed in future research.

\section{Conclusion}

The effectiveness of 4 weeks of Telephysiotherapy, after 2 weeks of supervised training was comparable to Supervised Physiotherapy treatment of 6 weeks on outcome measures of patients symptoms like pain, range of motion, strength, muscle flexibility, physical function, balance and proprioception, in patients with grade I and II Knee Osteoarthritis. There was additional benefit of low cost in Telephysiotherapy treatment. Thus, this mode of treatment can be considered in the management of patients with osteoarthritis of the knee.

\section{References}

Abbott JH, Robertson MC, Chapple C, et al.2013.Manual therapy, exercise therapy, or both, in addition to usual care, for osteoarthritis of the hip or knee: a randomized controlled trial. I: Clinical effectiveness. Osteoarthr Cartil.21:525-34.

Ağlamış, B., Toraman, N. F., \& Yaman, H. 2009. Change of quality of life due to exercise training in knee osteoarthritis: SF-36 and WOMAC. Journal of back and musculoskeletal rehabilitation, 22(1), 4348.

American Telemedicine Assocation about Telemedicine website. 2018. Retrived from http://www.americantelemed.org/main/about/about-telemedicine/telemedicine-faqs.

Azma, K., RezaSoltani, Z., Rezaeimoghaddam, F., Dadarkhah, A., \& Mohsenolhosseini, S. (2018). Efficacy of tele-rehabilitation compared with office-based physical therapy in patients with knee osteoarthritis: a randomized clinical trial. Journal of telemedicine and telecare, 24(8), 560-565.

Bellamy, N., Buchanan, W. W., Goldsmith, C. H., Campbell, J., \& Stitt, L. W. 1988. Validation study of WOMAC: a health status instrument for measuring clinically important patient relevant outcomes to antirheumatic drug therapy in patients with osteoarthritis of the hip or knee. The Journal of rheumatology, 15(12), 1833-1840.

Bennell, K., \& Hinman, R. 2005. Exercise as a treatment for osteoarthritis. Current opinion in rheumatology, 17(5), 634-640.

Bhatt, N. G., Sheth, M. S., \& Vyas, N. J. 2015. Correlation of fear avoidance beliefs with pain and physical function in subjects with osteoarthritis of knee (OA knee). Int $J$ Ther Rehabil Res, 4, 117-21.

Brennan, D. M., Mawson, S., \& Brownsell, S. 2009. Telerehabilitation: enabling the remote delivery of healthcare, rehabilitation, and self management. Stud Health Technol Inform, 145(231), 48. 


\section{Journal of Exercise Science \& Physiotherapy Vol. 16 No. 1 (January to June) 2020 \\ ISSN: 0973-2020 (Print) $\quad \mathrm{I}_{2} \mathrm{OR}$ Impact Factor $=6.850 \quad$ ISSN: 2454-6089 (Online)}

Carvalho, N. A. D. A., Bittar, S. T., Pinto, F. R. D. S., Ferreira, M., \& Sitta, R. R. 2010. Manual for guided home exercises for osteoarthritis of the knee. Clinics, 65(8), 775-780.

Cross M, Smith E, Hoy D, Ackerman, Fransen M, Bridgett L et al. 2014. The global burden of hip and knee osteoarthritis: estimates from the global burden of disease 2010 study. Ann Rheum Dis., 73(7):132330.

Deyle, G. D., Allison, S. C., Matekel, R. L., Ryder, M. G., Stang, J. M., Gohdes, D. D., ... \& Garber, M. B. 2005. Physical therapy treatment effectiveness for osteoarthritis of the knee: a randomized comparison of supervised clinical exercise and manual therapy procedures versus a home exercise program. Physical therapy, 85(12), 1301-1317.

Dicianno, B., Parmanto, B., Fairman, A., Crytzer, T., Yu, D., Pramana, G., Coughenour, D., Petrazzi, A. 2015. Perspectives on the evolution of mobile (mHealth) technologies and application to rehabilitation. Physical Therapy. 95:397-405.

Dinçer, F., Erol, Ö., \& Atalay, A. 2006. Effect of physical therapy on WOMAC scores and quality of life in patients with knee osteoarthritis. Journal of Musculoskeletal Research, 10(01), 57-61.

Diracoglu, D., Aydin, R., Baskent, A., \& Celik, A. 2005. Effects of kinesthesia and balance exercises in knee osteoarthritis. JCR: Journal of Clinical Rheumatology, 11(6), 303-310.

Ganjave Pranita, D., \& Twinkle, D. 2017. Efficacy of Neuromuscular Training on Pain, Balance and Function in Patients with Grade I and II Knee Osteoarthritis. Journal of Exercise Science \& Physiotherapy, 13(2).

Gosling, Artur Padão.2012. Physical therapy action mechanisms and effects on pain management. Revista Dor, 13(1), 65-70. https://doi.org/10.1590/S1806-00132012000100012

Jack Farr, I. I., Miller, L. E., \& Block, J. E.2013. Quality of life in patients with knee osteoarthritis: a commentary on nonsurgical and surgical treatments. The open orthopaedics journal, 7, 619.

Jamtvedt, G., Dahm, K.T., Holm, I. et al. 2008.Measuring physiotherapy performance in patients with osteoarthritis of the knee: A prospective study. BMC Health Serv Res 8, 145.

Jamtvedt, G., Dahm, K. T., Christie, A., Moe, R. H., Haavardsholm, E., Holm, I., \& Hagen, K. B. (2008). Physical therapy interventions for patients with osteoarthritis of the knee: an overview of systematic reviews. Physical therapy, 88(1), 123-136.

Jin, J., Sklar, G. E., Oh, V. M. S., \& Li, S. C.2008. Factors affecting therapeutic compliance: A review from the patient's perspective. Therapeutics and clinical risk management, 4(1), 269.

Kairy, D., Lehoux, P., Vincent, C., \& Visintin, M.2009. A systematic review of clinical outcomes, clinical process, healthcare utilization and costs associated with telerehabilitation. Disability and rehabilitation, 31(6), 427-447.

Kim, K., Lee, H. Y., \& Lim, S. J. 2016. Effects of increased standing balance on pain in patients with knee osteoarthritis. Journal of physical therapy science, 28(1), 87-89.

Multani, N. K., Singh, B., \& Garg, S. 2006. Effectiveness of telemedicine services integrated into physiotherapeutic health care system. Journal of Exercise Science and Physiotherapy, 2, 87.

Odole, A. C., \& Ojo, O. D.2013. A telephone-based physiotherapy intervention for patients with osteoarthritis of the knee. International Journal of Telerehabilitation, 5(2), 11.

Odole AC, Ojo OD.2014. Is telephysiotherapy an option for improved quality of life in patients with osteoarthritis of the knee? Int J Telemed Appl.;2014:1-9. doi: 10.1155/2014/903816.

Pal CP,Singh P, Chaturvedi S, Pruthi KK,Vij A. 2016. Epidemiology of knee osteoarthritis in India and related factors. Indian J Orthop, 50:518-22

Rao K, Iyer C, Anap D .2012. Can Telerehabilitation Add a New Dimension in the Treatment of Osteoarthritis Knee? J Pain Relief 2: 113. doi: 10.4172/2167-0846.1000113

Rogers, M. W., Tamulevicius, N., Coetsee, M. F., Curry, B. F., \& Semple, S. J. 2011. Knee Osteoarthritis and the Efficacy of Kinesthesia, Balance \& Agility Exercise Training: A Pilot Study. International journal of exercise science, 4(2), 124-132.

Russell, T. 2011. Tele-rehabilitation as successful as out-patient physiotherapy post total knee replacement. Journal of Bone and Joint Surgery, 93(2), 113-120.

Silva, A., Serrão, P. R., Driusso, P., \& Mattiello, S. M. 2012. The effects of therapeutic exercise on the balance of women with knee osteoarthritis: a systematic review. Rev Bras Fisioter, 16(1), 1-9. 


\section{Journal of Exercise Science \& Physiotherapy Vol. 16 No. 1 (January to June) 2020 \\ ISSN: 0973-2020 (Print) $\quad I_{2}$ OR Impact Factor $=6.850 \quad$ ISSN: 2454-6089 (Online)}

Sood, S., Mbarika, V., Jugoo, S., Dookhy, R., Doarn, C.R., Prakash, N. and Merrell, R.C., 2007. What is telemedicine? A collection of 104 peer-reviewed perspectives and theoretical underpinnings. Telemedicine and e-Health, 13(5):573-590.

Theodoros, D., Russell, T., \& Latifi, R. 2008. Telerehabilitation: current perspectives. Studies in health technology and informatics, 131, 191-210.

Tousignant, M., Moffet, H., Nadeau, S., Mérette, C., Boissy, P., Corriveau, H., ... \& Dimentberg, R. 2015. Cost analysis of in-home telerehabilitation for post-knee arthroplasty. Journal of medical Internet research, 17(3), e83.

Truter, Piers \& Russell, Trevor \& Fary, Robyn. 2013. The Validity of Physical Therapy Assessment of Low Back Pain via Telerehabilitation in a Clinical Setting. Telemedicine journal and e-health : the official journal of the American Telemedicine Association. 20. 10.1089/tmj.2013.0088.

Conflict of Interest: None declared 